\title{
La unión europea ante la crisis en la zona euro: reflexiones desde la historia y la política internacional
}

ACCESO Of ABIERTO

Para citaciones: Villasana, R. (2020). La unión europea ante la crisis en la zona euro: reflexiones desde la historia y la política internacional. El taller de la Historia, 12(2), 481-501.

Recibido: Agosto de 2020

Aprobado: Octubre de 2020

Autor de correspondencia: Ramiro Villasana Villalobos

lpmartinezm21@gmail.com

Editor: Sergio Paolo Solano. Universidad de Cartagena-Colombia.

Tipología IBN Publindex: Artículo de Investigación
Copyright: () 2020. Villasana, R. Este es un artículo de acceso abierto, distribuido bajo los términos de la licencia https://creativecommons.org/licenses/bync-sa/4.0/ la cual permite el uso sin restricciones, distribución y reproducción en cualquier medio, siempre y cuando que el original, el autor y la fuente sean acreditados.

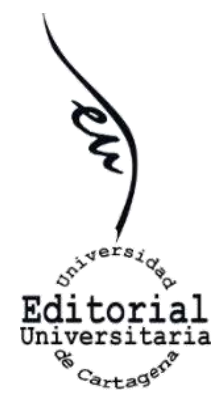

\section{RESUMEN}

En el presente artículo es realizada una descripción de las instituciones económicas de la Unión Europea, desarrollando algunos de los supuestos en torno a los orígenes y devenir de la política económica en este organismo; tomando como referente inicial la crisis financiera en la Europa comunitaria durante el presente siglo. Asimismo, se aborda el rol desempeñado por Alemania a lo largo de la recesión en la zona euro, dando a conocer algunas propuestas para la resolución de los problemas suscitados desde 2008. Finalmente, son revisadas algunas críticas al sistema de integración europeo y a su esbozo macroeconómico.

Palabras clave: Unión Europea; siglo XXI; Alemania; eurozona; recesión económica; instituciones.

\begin{abstract}
The aim of this text is to present the existing economic institutions in the European Union, developing some of the major issues surrounding the origins and evolution of European economic policy during this millennium, taking as initial reference the financial crisis the European Community. Also, it will describe the role played by Germany over the crisis in the euro zone presenting some proposals for the resolution of problems arising from 2008. Finally, will be reviewed some criticism to the system of European integration and their macroeconomic outline.
\end{abstract}

Keywords: European Union; XXI century; Germany; euro zone; economic recession; institutions.

\section{RESUMO}

Neste artigo é feita uma descrição das instituições econômicas da União Europeia, desenvolvendo algumas das premissas em torno das origens e tornando-se política econômica neste órgão; tendo como referência inicial a crise financeira na Europa Comunitária durante este século. Também aborda o papel desempenhado pela Alemanha durante toda a recessão na zona do euro, tornando conhecidas algumas propostas para resolver os problemas que surgiram desde 2008. Finalmente, algumas

${ }^{1}$ Doctor en Humanidades-Línea Historia, Universidad Autónoma Metropolitana-México 
críticas ao sistema de integração europeu e ao seu contorno macroeconômico são revisadas.

Palavras-chave: União Europeia, século XXI, Alemanha, zona do euro, recessão econômica, instituições.

\section{Introducción}

Desde hace varias décadas, el proceso de integración comunitario en Europa, ha sido uno de los temas de mayor cabida para investigadores en diferentes disciplinas. No obstante, es menester comprender que los factores que contribuyeron a la conformación de la actual Unión Europea, tienen sus orígenes desde hace varios siglos, manifestando un especial desarrollo a partir de un proceso acaecido en Europa entre 1939 y 1945: la Segunda Guerra Mundial.

Sumando a lo anterior, la presente investigación nace del interés por contribuir en el estudio metodológico, empírico-científico, en torno a la recesión económica en la zona euro en perspectiva histórica, tomando en consideración los fundamentos teóricos de la Política Internacional y las Relaciones Internacionales. Mediante el empleo de un cuadro metodológico mixto (con características cualitativas y cuantitativas), se pretende realizar una construcción retrospectiva del proceso y devenir del sistema de integración económico europeo, reflexionando en torno a sus procesos y fenómenos económico-políticos subyacentes.

Desde sus inicios en 2008, la crisis económica en la zona euro ha despertado la inquietud de politólogos y economistas, puesto que además de la situación financiera; el ámbito político, social y las relaciones internacionales han jugado un rol de gran relevancia en la determinación del camino seguido por la Unión Europea (UE) en su devenir como único organismo supranacional. Sin embargo, por tratarse de un proceso económico reciente, aún no ha sido abordado en perspectiva histórica.

En este sentido, el presente escrito buscará exponer, desde las historias política y económica, el proceso financiero y la recesión desarrollada en la zona del euro, analizando la posición de la UE frente a dicha problemática. Asimismo, serán descritas las atribuciones de las instituciones formales existentes en la UE, vinculándolas a lo sucedido con la zona euro, para establecer un bosquejo sobre los orígenes y devenir de la crisis económica en la Europa comunitaria, con base en algunas de las teorías existentes para la comprensión de las políticas implementadas en la comunidad europea.

Finalmente, se buscará reflexionar en torno al rol desempeñado por Alemania en el proyecto de integración europea durante el presente siglo, dando a conocer algunas de las alternativas que en su momento fueron propuestas para 
la solución de los problemas macroeconómicos de las naciones en crisis, estableciendo una proyección prospectiva en torno a los posibles escenarios futuros de la Unión Europea con base en la revisión de los procesos del pasado y una filosofía económica crítica-especulativa.

\section{La integración europea: antecedentes}

Tanto la Segunda Guerra Mundial como la Guerra Fría, pueden ser consideradas como dos importantes procesos que incentivaron la cohesión de las naciones en Europa. Es así como según la Comisión Europea, es posible ubicar las raíces de la Unión Europea a partir de la Segunda Guerra Mundial, ya que la idea de la integración europea tuvo su origen en evitar que volviera a suscitarse un conflicto bélico de tan gran magnitud. ${ }^{2}$

De los 50 millones de muertos que ocasionó la guerra, cerca de 37 millones de fallecidos fueron habitantes europeos, entre los que figuraron tanto civiles como militares, siendo 27 millones soviéticos, 6 millones de alemanes, 6 millones polacos, 300.000 austriacos, 444.500 italianos, 250.000 franceses, 385.000 británicos, entre otras múltiples víctimas. ${ }^{3}$

Además de la enorme cantidad de fallecidos, las pérdidas en otros ámbitos también resultaron catastróficas, ya que gran cantidad de ciudades europeas quedaron en ruinas, siendo las más afectadas las urbes de la Europa central y oriental. De igual forma, la producción alimentaria descendió a la mitad respecto a anteriores décadas a la guerra, mientras que la industria disminuyó a un tercio, siendo países enteros los que subsistieron de la caridad a partir de $1945 .^{4}$

De Acuerdo con Julio Gil, durante la Segunda Guerra Mundial todos los esfuerzos por la cohesión europea desarrollados en tiempos precedentes se vieron mermados, ya que este conflicto trajo consigo una nueva restructuración territorial del continente. Por su parte en 1940, Francia y el Reino Unido trabajaron en la proposición de una alianza impulsada por Jean Monnet, Arnold J. Toynbee, Arthur Salter, René Pleven y Robert Vasintart, en la cual se contemplaba una unión en el ámbito económico y de defensa contando con una ciudadanía común, iniciativa que el primer ministro británico Winston Churchill acepto, pero el presidente francés, Paul Reynaud, no logró que fuese admitida. ${ }^{5}$

Después de la Segunda Guerra Mundial el producto interno bruto de Francia había descendido un $46 \%$, el de Italia $40 \%$ y el de Alemania $71 \%$, el territorio europeo estaba destruido y las naciones tenían muy dañados sus transportes

\footnotetext{
${ }^{2}$ Comisión Europea, La historia de la Unión Europea, Madrid, Dirección de Prensa de la Comunidad Europea., 2005. http://ec.europa.eu/archives/publications/booklets/others/.../timeline_es.doc (Fecha de consulta: 23/07/2016).

${ }^{3}$ Ricardo Martin de la Guardia y Ricardo Pérez Sánchez, Historia de la integración europea, Ariel Ed. España: 2001, pp. 67-71.

${ }^{4}$ Ricardo Martin de la Guardia y Ricardo Pérez Sánchez, Historia de la, pp. 67-70.

${ }^{5}$ Julio Gil, Historia de la integración europea, Madrid, Universidad Nacional de Educación a Distancia Ed., 2011, pp. 2324.
} 
marítimos siendo sus flujos de mercancías precarios, al tiempo que se fue acumulando una gran deuda debido a las importaciones masivas que requerían de materia prima. ${ }^{6}$

Uno de los programas de apoyo con mayor relevancia para la reconstrucción de Europa, fue el denominado Plan Marshall, iniciativa estadounidense en la que tanto Canadá como los Estados Unidos constituyeron los máximos oferentes de apoyo económico y en especie para coadyuvar en la restauración de los países europeos, principalmente a través de la Organización Europea de Cooperación Económica (OECE). ${ }^{7}$

Al parecer ante el temor de que los países europeos fueran absorbidos por la Unión Soviética, el general norteamericano George Marshall, otorgó un discurso el 5 de mayo de 1947 en la Universidad de Harvard, en el que expresaba su preocupación por el pueblo europeo, mencionando que se ayudaría a todos que lo necesitasen, buscando retomar la democracia y la libertad a través del plan de contingencia. ${ }^{8}$

Días después del discurso se dio a conocer el Programa de Reconstrucción Europea (PRE), mejor conocido como Plan Marshall. Dicho plan se puso a cargo al diplomático George Kennan, quien estableció tres líneas de actuación: 1) los europeos deben tener iniciativa presentando un programa en el que ellos mismos sean quienes se hagan cargo; 2) el programa será abierto para cualquier país europeo; 3) su prioridad sería Alemania, ya que con la recuperación de este país se impulsaría al resto del continente. ${ }^{9}$

A diferencia de las condiciones experimentadas por las naciones de Europa, la nación estadounidense se consolidó en la posguerra como la primera potencia económica y militar a nivel global, caracterizándose por contar con el producto interno bruto con mejor crecimiento y la mayor parte de las divisas de oro mundial, siendo el primer exportador global para la década de 1940. ${ }^{10}$

Una de las distinciones que manifestó la relación entre las naciones europeas después de la primera y segunda guerras mundiales, es la aceptación que se manifestó hacia la nación alemana. A diferencia de lo suscitado al culminar la "Gran Guerra" (1918) en que se obligó a Alemania a pagar por las diversas perdidas, al finalizar la segunda guerra mundial, los Estados triunfantes optaron por coadyuvar en el desarrollo económico de Alemania, buscando una relación de amistad con tal país, al igual que con las otras naciones de la Europa capitalista. ${ }^{11}$

\footnotetext{
${ }^{6}$ Rafael Aracil, Joan Oliver Puigdomènech y Antoni Segura, El mundo actual: De la Segunda Guerra Mundial a nuestros días, Barcelona, Universitat de Barcelona Ed., 1998, pp. 65-67.

7 Guillermo Correa, "Retomando algunos conceptos teóricos para implementar en la práctica: orígenes, lógica y funcionamiento del sistema de Cooperación Internacional para el Desarrollo," en Directorio de Cooperación Internacional, Red Argentina para la Cooperación Internacional (RACI) Ed., 2012, pp. 30-34.

${ }^{8}$ Rafael Aracil, Joan Oliver Puigdomènech y Antoni Segura, El mundo actual, pp. 66-67.

${ }^{9}$ Rafael Aracil, Joan Oliver Puigdomènech y Antoni Segura, El mundo actual, pp. 68-70.

${ }^{10}$ Ricardo Martin de la Guardia y Ricardo Pérez Sánchez, Historia de la, pp. 71-73.

${ }^{11}$ Ricardo Martin de la Guardia y Ricardo Pérez Sánchez, Historia de la, pp. 73-76.
} 
Por lo anterior, es posible inferir que la segunda guerra mundial constituyó un elemento esencial para la integración de Europa, ya que a diferencia de otras conflagraciones en las que se acentúo el odio y la enemistad entre los Estados, durante los años cuarenta del siglo XX, los líderes de Francia, Gran Bretaña y Estados Unidos acordaron impulsar el progreso del país occidental germano, principalmente para evitar que un futuro descontento alemán produjese otro conflicto similar al iniciado en $1939 .{ }^{12}$

Por otra parte, en el año de 1948, entró en vigor la Unión Aduanera de Bélgica, Holanda y Luxemburgo, mejor conocida como Benelux, convenio por el cual tales estados capitalistas otorgarían pauta a la creación del primer mercado europeo con un arancel exterior común.

Puesto que el carbón y el acero constituían dos elementos fundamentales para las economías europeas desde la primera mitad del siglo XX, la creación de la Comunidad Europea del Carbón y del Acero (CECA) en 1951, también constituyó un acto fundamental para velar por los intereses y el progreso de los Estados en Europa. ${ }^{13}$

Haciendo uso de los supuestos de Charles Doran (2010), es posible inferir que la conformación de la Comunidad Europea del Carbón y el Acero, constituyó un importante producto de la cooperación entre las naciones europeas, el cual sentaría las bases hacia la integración comunitaria, contando como objetivo la preservación del status internacional que el continente europeo ejercía en el planeta en los decenios precedentes a la guerra. ${ }^{14}$

En este sentido, tanto la colaboración como la competencia se vincularon en Europa de una manera estratégica, ya que la cohesión interestatal europea, figuró durante la segunda mitad del siglo XX como una herramienta clave para competir económica y políticamente contra las dos principales potencias que emergieron en la posguerra con la mayor relevancia global, siendo tales la URSS y los Estados Unidos.

Otro de los postulados que podría ser aplicado al proceso de integración en Europa, son los postulados del historiador Arnold J. Toynbee, quien en sus presupuestos señala que una comunidad "nace y comienza a existir como consecuencia de la respuesta que un grupo humano de al reto que le presenta un medio natural o social." 15

Es decir que de acuerdo a la teoría del reto-respuesta expuesta por Toynbee, una comunidad es capaz de existir y evolucionar debido a la existencia de

\footnotetext{
12 Froylán Enciso, Andar fronteras: el servicio diplomático de Octavio Paz en Francia (1946-1951), Siglo XXI Ed., México, 2008, p. 100

${ }^{13}$ Enriqueta Serrano Caballero, Pasado, presente y futuro de la cooperación de la Unión Europea hacia México, El Colegio de San Luis Ed., 2008, p. 15.

${ }^{14}$ Charles Doran, "Las dos caras de la cooperación multilateral," en William Zartman, W. \& Saadia Touval, International Cooperation. Cambridge University Press Ed. Estados Unidos, 2010, pp. 50-52.

${ }^{15}$ RIONDA Arreguín Luis, Reflexiones en torno a la Historia, México, Universidad de Guanajuato Ed., 1998 , p. 114.
} 
necesidades, de modo que los pueblos sobreviven, prosperan o evolucionan gracias a la búsqueda de nuevos retos y satisfacciones. ${ }^{16}$

Es posible inferir que, la colaboración entre las naciones euro-occidentales para la conformación de tres comunidades europeas en seis años (19511957), ${ }^{17}$ fue impulsada por la necesidad de fortalecer sus economías y capacidad armamentista, optando por la integración para abastecerse por sí mismas de lo necesario para su reconstrucción y desarrollo, en tanto que, con la creación de la Comunidad Económica Europea (1957), se incrementó el poder económico euro-capitalista frente a la Europa bajo el área de influencia soviética, integrándose así diversos países que en décadas precedentes habían sido acérrimos rivales, tal como en el caso de Alemania y Francia, quienes desde siglos precedentes habían sido enemigos en innumerables conflictos. ${ }^{18}$ Asimismo, el papel de seis instituciones precedentes al Consejo de Europa, fue fundamental para la creación de la Europa comunitaria, siendo tales: Unión Europea de Federalistas (UEF), El Movimiento Social por los Estados Unidos de Europa (MSEUE), Liga Europea de Cooperación Económica (LECE), Los Nuevos Equipos Internacionales (NEI), Movimiento para la Europa Unida (MEU) y La Unión Parlamentaria Europea (UPE). ${ }^{19}$

Finalmente, como un bloque integrado en el ámbito económico y político, cabe mencionar que la Comunidad Europea adquirió durante la segunda mitad del pasado siglo un importante prestigio a nivel global, ya que al consolidarse como un organismo supranacional pudo exportar sus modelos de política democrática y de respeto a los derechos humanos a diferentes regiones del planeta.

\section{Las instituciones económicas de la unión europea}

De acuerdo con el paradigma histórico-económico Neo Institucional, para comprender la realidad económica de las naciones, es necesario explicar cómo las instituciones generan formas de comportamiento, hábitos y creencias, analizando el por qué los organismos económicos devienen históricamente de cierta forma y no de otra: ${ }^{20}$ "las instituciones son las "reglas del juego" que norman y moldean el comportamiento de los actores económicos." 21

En este paradigma teórico, son objetos de estudio dos clases de instituciones: formales e informales. Entre las primeras figuran los códigos, constituciones, leyes, contratos y otros organismos que generalmente son plasmados o

\footnotetext{
16 Amitai Etzoni y Eva Etzoni, Los cambios sociales. Fuentes, tipos y consecuencias, México, Fondo de Cultura Económica Ed., 1968, pp. 34-35; TOYNBEE, Arnold, Estudiodela Historia (1ra Ed. 1934), Emece Ed., Argentina, 1951, p. 308.

${ }^{17}$ Comunidad Europea del Carbón y del Acero (1951), Comunidad Europea de la Energía Atómica (1957) y la Comunidad Económica Europea (1957).

${ }^{18}$ Sven Held, "Las relaciones entre América Latina y la Comunidad Económica Europea: esperanzas y perspectivas," en Revista Nueva Sociedad, Núm. 31, 1977, pp. 54-56.

${ }^{19}$ Julio Gil, Historia de la, pp. 49-53.

${ }^{20}$ Claude Ménard y Mary Shirley, Handbook of New Institutional Economics, Berlin, Springer-Verlag Ed., 2005, pp. 1-9.

21 Sandra Kuntz Ficker, Historia económica general de México, Distrito Federal, El Colegio de México Ed., 2010 , p. 23.
} 
creados por escrito, mientras que las instituciones informales constituyen las normas de comportamiento social que suelen ser premiadas o sancionadas: acuerdos, códigos de conducta y formas de proceder que provienen de las costumbres, tradiciones y cultura. ${ }^{22}$

En este sentido, para Douglas North "el cambio institucional conforma el modo en que sociedades evolucionan a lo largo del tiempo, por lo cual es la clave para entender el cambio histórico." 23 A pesar de la importancia que conllevan las normas informales, es necesario conocer las organizaciones formales en primera instancia para comprender los procesos económicos en la historia. ${ }^{24}$ Por ello, para comprender el impacto y los orígenes de la recesión económica en Europa, este estudio se enfocará principalmente en las instituciones formales de la UE y su relación con la zona euro.

Actualmente son siete las instituciones encargadas de coadyuvar en el desarrollo económico de la Unión Europea y favorecer a las naciones pertenecientes a la zona euro: el Comité Económico y Social, el Tribunal de Cuentas, la Comisión Europea, el Comité de las Regiones, el Banco Europeo de Inversiones, el Banco Central Europeo y el Fondo Europeo de Inversiones. ${ }^{25}$

En primera instancia, la Comisión Europea es la encargada de gestionar el presupuesto de la Unión Europea y asignar los fondos en conjunto con el consejo y el parlamento. La Comisión establece las prioridades generales de gasto a largo plazo para la Unión en lo que se denomina el "marco financiero." Esta también elabora el presupuesto anual y supervisa el uso dado a los fondos de la UE. Asimismo, gestiona los fondos que se destinan a las políticas de agricultura y desarrollo rural y algunos programas de cooperación internacional como Erasmus (becas de intercambio académico). ${ }^{26}$

Con sede en Luxemburgo, el Tribunal de Cuentas de la Unión Europea, es aquél que controla todas las actividades financieras de la comunidad, comprobando tanto la legalidad como la regularidad de los ingresos y gastos en conformidad con las normas y reglas vigentes en la comunidad europea. Conformado por 836 agentes de los países miembros, este organismo funge como auditor externo de los intereses financieros de los ciudadanos de la $\mathrm{UE}^{27}$

En cuanto al Comité Económico y Social, es un órgano consultivo plurilateral e interdisciplinario compuesto por 222 representantes de los diferentes

\footnotetext{
22 S. Kuntz Ficker, Historia económica general, pp. 23-27.

${ }^{23}$ Douglass North, Instituciones, cambio institucional y desempeño económico, México, Fondo de Cultura Económica Ed., 2012, p. 13.

${ }^{24}$ S. Kuntz Ficker, Historia económica, pp. 26-27.

${ }^{25}$ Comisión Europea, La historia de, s. p.

${ }^{26}$ Francesco Morata, La Unión Europea. Procesos, actores y políticas, Barcelona, Ariel Ed., 1999, pp. $133-138$.

${ }^{27}$ Rodolfo Cruz Miramontes, Las relaciones comerciales multilaterales de México y el Tratado de Libre Comercio con la Unión Europea, México, Universidad Nacional Autónoma de México Ed., 2003, p. 145; Unión Europea, Tribunal de Cuentas Europeo. Informe Anual de Actividades 2007, Luxemburgo, Oficina de publicaciones oficiales de las comunidades europeas Ed., 2008, pp. 6, 38.
} 
sectores económicos europeos, tales como los productores, agricultores, comerciantes, profesionistas y artesanos, entre otros. Cabe mencionar que este órgano debe ser consultado obligatoriamente antes de adoptar decisiones, ya que de lo contrario se puede anular una resolución adoptada con respecto a los sectores antes mencionados; además cuenta con la capacidad de emitir dictámenes por iniciativa propia. ${ }^{28}$

Creado en 1957, el Banco Europeo de Inversiones (BEI) tiene como objetivo financiar los proyectos de la Unión Europea. Esta institución colabora para lograr los objetivos de la Unión a través de proyectos de inversión que promuevan la integración europea, el desarrollo equilibrado, la cohesión económica y una economía innovadora basada en el conocimiento. ${ }^{29}$

Dicho organismo es financiado por los Estados miembros de la Unión Europea, mismos que suscriben conjuntamente su capital mediante contribuciones que reflejan su peso económico en la comunidad europea, figurando como un elemento más para la favorecer la integración y la cooperación económica. Además, los proyectos del BEI tienen como finalidad hacer más competitivas a las industrias europeas y a las pequeñas empresas, creando redes transeuropeas que beneficien a las regiones más desfavorecidas, principalmente en sectores como transporte, telecomunicaciones y energía. ${ }^{30}$

Sin duda, otro de los organismos económicos de importancia en la UE, es el Banco Central Europeo (BCE), debido a que es el responsable de fijar la política económica y monetaria de la Europa comunitaria junto con su aplicación, además de que protege la estabilidad de los precios en la Unión Europea. ${ }^{31}$

Con sede en Fráncfort, Alemania, el BCE cuenta entre sus atribuciones el establecer los tipos de interés fundamentales para la zona del euro y controlar la oferta de dinero, autorizar la emisión de euros a los bancos centrales de los países de la eurozona, vigilar la evolución de los precios y evaluar el riesgo que tal supone para su estabilidad, entre otras funcionalidades. Cabe destacar que desde el tratado de Maastricht (1992), se compone de tres órganos decisorios: comité ejecutivo, consejo general y consejo de gobierno. ${ }^{32}$

Respecto al Comité de las Regiones, cabe destacar que se encarga de colaborar en el desarrollo de las naciones con mayores limitaciones, reactivar los espacios económicos-industriales en decadencia, combatir el desempleo e innovar las estructuras agrícolas y silvícolas para favorecer el desarrollo de las zonas rurales. ${ }^{33}$

\footnotetext{
${ }^{28}$ Rodolfo Cruz Miramontes, Las relaciones comerciales, pp. 145-146.

${ }^{29}$ Local Europe, European consulting. Banco Europeo de Inversiones, Madrid, Green Europe Ed., 2013.

http://greeneurope.es/docs/Banco\%20Europeo\%20de\%20Inversiones\%202013.pdf (Fecha de consulta: 23/07/2017).

${ }^{30}$ Local Europe, Banco Europeo de, pp. 9-10, 22-24.

${ }^{31}$ Francesc Morata, La Unión Europea, pp. 211-213.

32 Francesc Morata, La Unión Europea, pp. 210-217.

${ }^{33}$ Rodolfo Cruz Miramontes, Las relaciones comerciales, pp. 146-147
} 
Finalmente, creado en 1993, el Fondo Europeo de Inversiones, constituye un instrumento financiero de gran solidez e importancia, cuya principal función radica en la aportación de capital para el desarrollo de las pequeñas y medianas empresas.

Asimismo, el fondo coadyuva en la promoción a la iniciativa privada, el fomento al desarrollo tecnológico y colabora en la creación de un entorno financiero adecuado para estimular el crecimiento económico y el empleo en las diversas regiones de la Unión Europea. ${ }^{34}$

\section{La recesión en la zona euro}

El comienzo de la crisis en la eurozona se remonta a los primeros años de su creación, ya que, al iniciar la primera década del siglo XXI, se dio pauta al financiamiento de múltiples programas para el bienestar de la población en diversas naciones europeas, manifestando un exceso de gasto respecto al ahorro con que contaban las economías nacionales, al tiempo que se otorgaron elevados salarios a cambio de pocas horas de trabajo. ${ }^{35}$

Posteriormente, como consecuencia de un exceso de confianza en el Euro como moneda atractiva para la inversión, tanto las empresas como los gobiernos tendieron a endeudarse en gran medida, lo cual ocasionó que algunos Estados se quedaran sin recursos para pagarle a los bancos, trayendo consigo así una falta de liquidez para las instituciones financieras que le prestaron a naciones incapaces de pagar su endeudamiento, tal como fue el caso de España. ${ }^{36}$

De igual manera, a raíz de la escasez de dinero y la desaceleración de la economía, la fuga de las inversiones no se hizo esperar; por tales motivos los gobiernos de las naciones con industrias poco competitivas no pudieron continuar ofreciendo el grado de bienestar que habían proporcionado anteriormente a sus habitantes. ${ }^{37}$

Debido a que en naciones como España su economía se fundamentó principalmente en sectores como el Turismo, tuvo lugar un auge en el empleo para la construcción de viviendas y la remodelación de sus edificios en años precedentes a la crisis, mientras que las manufacturas y las otras industrias se volvieron cada vez menos competitivas respecto a naciones como Alemania, país del que se importaron la mayor cantidad de bienes en la península europea durante las últimas décadas. ${ }^{38}$

\footnotetext{
${ }^{34}$ Antonio Fernández Álvarez, "El fondo europeo de inversiones: pieza clave de la financiación PYME en la Unión Europea," en Boletín económico de Información Comercial Española (BICE), No. 3014, 2011, pp. 21-24.

${ }^{35}$ Ricardo Ávila, "Radiografía de la crisis en la eurozona," en Portafolio: Noticias de economía y negocios en Colombia y el Mundo, Bogotá, Centro de Información Económica, 2012. http://www.portafolio.co/especiales/crisis-en-europa (Fecha de consulta: 11/12/2018).

36 Paul Krugman, “¿Realmente se salvará al euro?,” en El Universo, New York Times News, Quito, 2012. http://www.eluniverso.com/2012/08/08/1/1363/realmente-salvara-euro.html. Fecha de consulta: 11/12/2015.

37 Amartya Kumar Sen, “¿Qué le pasó a Europa? La democracia y los banqueros,” en Nexos, No. 418, 2012, pp. 54-55.

${ }^{38}$ Amartya Kumar Sen, “Qué le pasó,” pp. 54-56.
} 
Con base en lo anterior es posible apreciar como Alemania no perdió su competitividad internacional, ni fue afectada fuertemente por la recesión económica, puesto que en los años de bonanza se vio beneficiada por las compras de múltiples naciones, entre las que figuraron España, Irlanda, Portugal y Grecia. Estos países posteriormente no pudieron vender los inmuebles que adquirieron y crearon, encontrándose en desventaja sobre la productividad en otros sectores económicos, especialmente a partir de la fuga de capitales y las fuertes restricciones impuestas para la adquisición de créditos. ${ }^{39}$

A partir del 2008 el sector privado en diversas naciones de Europa manifestó una seria problemática: las propiedades que había adquirido en los años de bonanza también se volvieron difíciles de vender. Ello fue consecuencia de la pérdida del poder adquisitivo de los ciudadanos, quienes, en los años precedentes, pudieron acceder con facilidad a diferentes préstamos y pagos a largo plazo.

Por tal motivo, el gobierno de algunas naciones tuvo que pagar por lo que no podían los individuos a quienes los bancos les prestaron, generando otro endeudamiento más para los Estados en crisis. ${ }^{40}$

Al finalizar la primera década del siglo XXI, fueron implementados algunos rescates para salvar a los bancos, estableciendo la UE la inyección de capitales en los países con incapacidad de cubrir sus deudas a las instituciones financieras. Igualmente, fueron puestas en marcha diversas medidas de austeridad para reducir los gastos de las naciones con mayores problemas económicos. ${ }^{41}$

A pesar de la pretensión manejada en teoría, de acuerdo con Paul Krugman, los planes de austeridad solo profundizaron la crisis, al tiempo que la masiva fuga de inversiones y la desaceleración de la economía provocaron el incrementó desempleo a niveles alarmantes en diferentes naciones. ${ }^{42}$

\section{El papel de Alemania en la política económica europea}

En el año 2010, el gobierno alemán encabezado por Angela Merkel manifestó su posición respecto a la crisis desatada en Grecia, Portugal e Irlanda, señalando que cualquier "plan de rescate" económico del bloque europeo, sólo podría materializarse si fuese cofinanciado por el Fondo Monetario

\footnotetext{
${ }^{39}$ Elena Sanz, "La agonía de tres mercados inmobiliarios: España, Grecia e Irlanda," en El confidencial, Madrid, Titania, 2011. http://www.elconfidencial.com/vivienda/2011-10-13/la-agonia-de-tres-mercados-inmobiliarios-espana-grecia-eirlanda 209477/ (Fecha de consulta: 22/07/2019)

40 Eva Llorca, Solicitar un crédito en España, ¿misión imposible?, en La Nueva España, Asturias, 2012. http://www.Ine.es/finanzas-personales/2012/09/26/solicitar-credito-espana-mision-imposible/1303653.html (Fecha de consulta: 23/07/2020).

${ }^{41}$ Consejo Europeo, Declaración de los Jefes de Estado y de Gobierno de la Zona del Euro, Bruselas, Dirección General de Prensa y Comunicación de la Unión Europea, 2011, pp. 3, 4, 6.

${ }^{42}$ Paul Krugman, "A menos que España abandone el euro está condenada a años de paro elevado," en El Economista, España, 2012. http://www.eleconomista.es/espana/noticias/4286867/09/12/Paul-Krugman-A-menos-que-Espanaabandone-el-euro-esta-condenada-a-anos-de-paro-elevado.html (Fecha de consulta: 22/07/2016)
} 
Internacional (FMI) y otros apoyos bilaterales directos de diversos países que deseasen ayudar a las naciones en crisis. ${ }^{43}$

Sin embargo, en octubre de 2011, el gobierno germano incrementó su porcentaje de cuota para la UE, pasando de 4 a $9 \%$, al tiempo que logró en la cumbre naciones que la deuda griega se recortara en un 50\%. Dos meses después el consejo europeo publicó algunas de las propuestas que se llevarían a cabo en la unión europea para otorgar solución a la crisis y evitar posteriores conflictos económicos. Tales fueron:

- El déficit estructural anual de cada país de la UE no deberá superar el $0.5 \%$ de su Producto Interno Bruto (PIB), lo cual se verificará en su cumplimiento a través del Tribunal de Justicia de la Unión Europea.

- Se otorgarán sanciones automáticas a los países que superen el límite del 3\% de déficit.

- Se dará apertura a la aprobación de un empréstito al FMI por un valor de 200 mil millones de Euros, con la finalidad de asistir a los países más debilitados económicamente. ${ }^{44}$

Puesto que la principal entidad económica de la zona euro se encuentra en Alemania, y es tal la nación en mejores condiciones económicas de la UE, tanto el Banco Central Europeo como el gobierno alemán, además de jugar un rol controversial para la economía de varias naciones, también han ejercido un papel significativo en el rescate financiero europeo. No obstante, se argumenta que esto solo ha sido posible debido a la fuerte demanda que le han solicitado a Berlín para inyectar capital algunas de las naciones en crisis. $^{45}$

Aunque Angela Merkel expresó en febrero de 2010 que no se otorgarían apoyos financieros, Alemania proporcionó más de 200,000 millones de euros (en préstamos y garantías de créditos) a los miembros de la eurozona con problemas, al tiempo que el BCE ha desempeñado una función clave para salvar a diversas naciones de la falta de pago en sus deudas. Es así como éste último ha ido ejerciendo otras funciones, además de la vigilancia para la estabilidad monetaria que se planteó como única responsabilidad en sus inicios. $^{46}$

Como consecuencia de su poder económico, el poder político alemán se ha convertido en un hecho evidente en la Unión Europea, ya que en ocasiones Alemania se ha impuesto sobre las ideas de los demás Estados miembros, principalmente a raíz de la dependencia que han manifestado los países de la

\footnotetext{
${ }^{43}$ Juan Pablo Jarufe, y Nicole Scharrer, Crisis económica europea: origen, alcances y principales actores involucrados, Santiago de Chile, Comisión Permanente de Relaciones Exteriores Ed., 2012. http://resmn.es/crisis-econmica-europeaorigen-alcances-y-principales-actores.html (Fecha de consulta: 23/07/2017).

${ }^{44}$ Consejo Europeo, Declaración de los, pp. 3, 4, 6.

${ }^{45}$ GAZETA Wyborcza, UNIÓN EUROPEA: El fin de la Europa alemana, Varsovia, Vox europ Ed., 2012, p. 105. http://www.voxeurop.eu/es/content/article/2220431-el-fin-de-la-europa-alemana (Fecha de consulta: 23/07/2018).

${ }^{46}$ GAZETA Wyborcza, UNIÓN EUROPEA: P. 105.
} 
UE sobre la economía germana. Esto debe a que dicha nación proporciona alrededor del veinte por ciento del presupuesto de la Unión Europea. ${ }^{47}$

\section{Relaciones de poder en la Europa comunitaria}

De acuerdo Kenneth Waltz, las capacidades económicas no pueden ser separadas de otras capacidades con que cuentan los Estados, debido a que dichas entidades suelen hacer uso de sus medios económicos para conseguir más de ellos y concretar determinados fines políticos o militares, es decir que existe una interdependencia entre la esfera económica y el ámbito político. ${ }^{48}$

Haciendo uso del anterior presupuesto, cabe especular que una de las razones por las que Alemania ha constituido la nación que lidera la política económica de la UE, es por el hecho de contar con la capacidad económica más significativa y el mayor porcentaje de aportaciones financieras para la comunidad europea. Al existir cierta dependencia en las naciones de Europa sobre las exportaciones y capitales otorgados por Alemania, es posible inferir que las negociaciones suelen inclinarse a favor de lo que el gobierno alemán propone durante las cumbres celebradas entre los líderes nacionales europeos.

Según lo señalado por internacionalistas como Robert Keohane y Joseph Nye, cuando existe alguna clase de dependencia por parte de uno o más Estados respecto otro, las entidades políticas que se encuentran implicadas suelen verse afectadas de forma significativa por tal país. ${ }^{49}$

En el caso del poder económico, ha servido en cierta forma para otorgar los resultados deseados por Alemania en Europa, como consecuencia de ser la nación que posee dicha ventaja; destacando como la comunidad más requerida para combatir la crisis y el país con menor dependencia de otros miembros de la Europa comunitaria. ${ }^{50}$

De acuerdo con Kenneth Waltz, el poder es definido en términos de capacidades, en el sentido de que un agente ejerce el poder conforme un Estado logra que otro llegue a comportarse de acuerdo a sus requerimientos. Similar a la tal percepción, para Robert Keohane y Joseph Nye, el poder es concebido como el potencial para afectar o determinar los resultados y la habilidad de un actor para que otros realicen lo que de otro modo no harían, respecto a ello, es posible expresar que Alemania cuenta con tal privilegio. ${ }^{51}$

\footnotetext{
${ }^{47}$ Fernando Heller, Berlín sigue marcando el paso, en La nación, Buenos Aires, 2010. http://www.lanacion.com.ar/1272904berlin-sigue-marcando-el-paso (Fecha de consulta: 23/06/2020).

${ }^{48}$ Kenneth Waltz, El poder y las relaciones internacionales, México Distrito Federal, Centro de Investigación y Docencia Económicas Ed., 2005, p. 18.

${ }^{49}$ Robert Keohane y Joseph, Nye, "La interdependencia en la política mundial," en Interdependencia, cooperación y globalismo, Ensayos escogidos de Robert O. Keohane, (ed.) Arturo Borja Tamayo (Ciudad de México: Centro de Investigación y Docencia Económicas, 2009, pp. 101,105.

${ }^{50}$ Robert Keohane, Interdependencia, cooperación y globalismo: Ensayos sobre las Instituciones Internacionales, Ciudad de México, Centro de Investigación y Docencia Económicas Ed., 2005, pp. 101,105-106; Axel Bertuch y Parmeshwar Ramlogan, "The euro ever more global," en Finance and Development, Vol. 44. No. 1, 2007, pp. 46-49.

51 Robert Keohane y Joseph, Nye, La interdependencia en, pp. 105-106; Kenneth Waltz, El poder y, p. 17.
} 
La anterior aseveración, es ejemplificada en el caso de lo pretendido por naciones como Francia o España respecto a la supervisión financiera de la UE, puesto que, en la cumbre celebrada entre los jefes de Estado en 2012, el gobierno alemán logró establecer que tal revisión futura sólo llegue a realizarse en los bancos europeos con recursos superiores a los 30,000 millones de euros. ${ }^{52}$

Además, manifestando una contradicción con los economistas, el Estado alemán fue logrando ajustar a sus necesidades diversos proyectos políticos de la UE, figurando entre ellos, el aplazamiento de la Unión Bancaria para la comunidad europea y la anulación de la propuesta del presidente del Consejo Europeo (Herman Van Rompuy) sobre compartir la deuda de las naciones en crisis $^{53}$.

\section{La situación en la eurozona durante el tercer milenio}

Durante el presente siglo, han sido identificadas dos principales tendencias respecto a la zona euro, ya que hay quienes pretenden la total integración entre los Estados de Europa catalogados como eurofilos, mientras que otros abogan por la permanencia de la soberanía nacional y son conocidos como euroescépticos..$^{54}$

Según lo señalado por Amartya Sen, la Unión Europea se ha encontrado en una búsqueda por la supervivencia del Euro; planteando principalmente proporcionar liquidez a los países en problemas por medio de diversas alternativas, tales como los paquetes de rescate garantizados por los países económicamente más fuertes o la compra de bonos y la recaudación de impuestos para influir en la economía. ${ }^{55}$

La política que exigió el gobierno alemán y el BCE a los Estados en crisis devino en una fórmula anti crecimiento. En este sentido, a excepción de Alemania, el PIB en toda la zona euro no hizo más que caer desde que se implementaron las medidas de austeridad con algunos rescates. ${ }^{56}$

La gravedad de la situación fue bastante, puesto que el reporte de crecimiento cero en la zona del euro (tomando en cuenta todos sus Estados miembros) durante el primer trimestre de 2012 fue ampliamente recibido como una "buena noticia". Es así como España, Portugal e Italia, agravaron su crisis a lo largo del 2012 al tiempo que la economía griega, perdió un cuarto en su producción desde el 2008. ${ }^{57}$

\footnotetext{
52 Claudi Pérez, "Alemania marca el paso en la UE," en El País, Madrid, 2012. http://economia.elpais.com/economia/2012/12/06/actualidad/1354826887_993406.html (Fecha de consulta: 23/07/2016).

${ }_{53}^{53}$ Fernando Heller, Berlín sigue marcando, (s. p.).

${ }^{54}$ Jason Saving, "Integration and Globalization: The European Bellwether," en Economic Letter, Vol. 1. No. 5, 2006, p. 6.

${ }_{55}^{55}$ Amartya Kumar Sen, Qué le pasó, pp. 55-56.

${ }^{56}$ Jourdy James Heredia, Informe sobre la Evolución de la Economía Mundial 2012, La Habana, Centro de Investigaciones de la Economía Mundial Ed. 2013, pp. 18-24.

${ }^{57}$ Amartya Kumar Sen, ¿Qué le, pp. 54-56?
} 
Sumado a la percepción del economista de la India, para Paul Krugman, la acentuación de la crisis también es producto de la falta de unidad entre los Estados de Europa, ya que, al realizar una comparación con lo sucedido en Estados Unidos, Krugman señaló que, en el caso de España y Florida, aunque ambas tuvieron crisis derivadas del sector inmobiliario. ${ }^{58}$

A diferencia de España, al desatarse la recesión en Florida, dicha entidad pudo contar con que Washington continuó pagando la seguridad social, garantizando la solvencia de sus bancos y proporcionando ayuda de emergencia a sus desempleados, mientras que España no contó con dicha red de seguridad económica por parte de los Estados de mayor riqueza en Europa. ${ }^{59}$

Por lo señalado, una de las principales críticas hacia Alemania y a otras naciones de Europa, ha sido si tales Estados realmente piensan en la Unión Europea $\mathrm{o}$ en sus respectivas naciones, en el sentido de que podría vislumbrarse como necesario para salvar al euro y resolver la crisis el aumento de la solidaridad en la comunidad europea.

Asimismo, entre las soluciones que se han manifestado respecto a la crisis de Europa, cabe destacar la propuesta de implementación de una política fiscal común en la Unión Europea. Según algunos supuestos, si los niveles de deuda pública fuesen homogéneos entre todos los Estados miembros de la UE, las naciones con más dificultades para vender su deuda por sus altos intereses, dejarían de manifestar tal problemática, quedando establecido un interés igual para todos los Estados miembros. ${ }^{60}$

No obstante, lo expresado, para países que no cuentan con problemas respecto a la emisión de deuda, tales como Alemania, se verían afectados por esta política, debido a que podrían pagar más con el establecimiento de una tasa de interés común para la totalidad de miembros de la comunidad económica europea. ${ }^{61}$

Igualmente, otra alternativa que se ha planteado respecto a la crisis en naciones como España ha sido su salida del Euro, puesto que, si volviese a contar con la peseta u otra moneda con flexibilidad de cambio, se podría devaluar la misma y atraer turismo, elemento con el cual la nación podría reactivar su economía. ${ }^{62}$

Además de reevaluar su moneda, durante crisis precedentes, naciones como México y Estados Unidos emprendieron diversas estrategias para combatir las recesiones y reactivar sus economías relativamente rápido. En este

\footnotetext{
58 Paul Krugman, "Realmente se salvará, (s. p.)

59 Paul Krugman, "Realmente se salvará, (s. p.)

${ }^{60}$ Jourdy James Heredia, Informe sobre la, 20-27.

61 Jourdy James Heredia, Informe sobre la, pp. 18-25.

${ }^{62}$ Paul Krugman, ¿Realmente se salvará?, (s. p.)
} 
sentido, la prohibición en cuanto al uso las monedas de plata y su exportación figuraron entre las medidas del Estado mexicano durante la Gran Depresión de $1929 .{ }^{63}$

Lo anterior tuvo como objetivo, hacer de los billetes emitidos por el Banco de México la única moneda de circulación legal en el país, lo que contribuyó en otorgarle la capacidad de regular la circulación monetaria al Banco Central mexicano, favoreciendo la restauración de los precios y la independencia del sistema monetario respecto al valor internacional del oro y la plata. ${ }^{64}$

Por otra parte, el presidente demócrata Franklin Delano Roosevelt, impulsó en Estados Unidos diversas agencias y políticas encaminadas a la protección social durante la década de 1930, con base en el llamado "nuevo trato" o New Deal para la transformación económica. ${ }^{65}$

Con similitud a los casos expuestos, puesto que diversas naciones contaban con capacidad productiva en desuso y un alto desempleo, en los años treinta del pasado siglo se buscó reactivar a las economías en crisis con la intervención del Estado; principalmente a través de programas que impulsaran la creación de espacios laborales en las naciones capitalistas. ${ }^{66}$

\section{La crisis económica y la Unión Europea}

Entendida como el hecho de que un actor padezca costos impuestos por acontecimientos externos, la vulnerabilidad constituye una de las características que tienen lugar en los Estados con alguna clase de dependencia. En este sentido, el hecho de contar con el Euro incrementó el grado de vulnerabilidad económica para las naciones que hoy en día están en crisis, recordando que el tipo de cambio fijo es determinado por las instituciones de la UE, lo cual les impide ejercer el control sobre su política monetaria. $^{67}$

Con base en lo anterior, al no poder devaluar su moneda, una nación no puede volverse más barata para vender bienes o servicios, ya que hoy en día es necesario contar con un fuerte poder adquisitivo para visitar las naciones de la UE. Por tal motivo, el acceso a capitales extranjeros se ha mermado, al tiempo que los países cuyo sector turístico aportaba fuertes ganancias se han visto seriamente afectados: a pesar de modificar su consumo interno, fueron perjudicados por la dependencia que tenían del consumo externo. ${ }^{68}$

\footnotetext{
${ }^{63}$ Enrique Cárdenas, El largo curso de la economía mexicana. De 1780 a nuestros días, Ciudad de México, El Colegio de México Ed., 2015, pp. 444-446.

${ }^{64}$ Enrique Cárdenas, El largo curso, pp. 445-447.

${ }^{65}$ Carlos Marichal, Nueva historia de las grandes crisis financieras: una perspectiva global 1873-2008, Ciudad de México, Debate Ed., 2010, pp. 123-126.

${ }^{66}$ Ramiro Villasana Villalobos y Rafael Salvador Espinosa Ramírez, La inversión extranjera directa española en México: fundamentación y retrospectiva (1950-2013), Guadalajara, Universidad de Guadalajara Ed., 2015, pp. 29-30.

67 Robert Keohane y Joseph, Nye, La interdependencia en, p. 109.

68 Paul Krugman, "Grecia, España y el euro," Quito, en El Universo, 2010. http://www.eluniverso.com/2010/02/19/1/1363/grecia-espana-euro.html (Fecha de consulta: 22/07/2017).
} 
Además, generalmente las naciones europeas en recesión no contaron con la capacidad para competir internacionalmente en la producción a gran escala y a bajo costo en múltiples bienes, elemento que volvió a tales Estados, entidades más vulnerables respecto a países europeos más productivos. ${ }^{69}$

De acuerdo con Karen Mingst, existen tres niveles de análisis desde los cuales es posible comprender el actuar político y los fenómenos existentes en las relaciones interestatales, siendo tales: individual, estatal e internacional. El primero de estos (individual), se caracteriza por explicar un asunto reflexionando en torno a las elecciones de los actores que orientan una problemática de acuerdo a su personalidad, percepciones y otras características personales. $^{70}$

Haciendo uso de la categoría de análisis individual y, tomando como principal referente a Angela Merkel, es posible suponer que su proceder respecto a la proposición e imposición de los estrictos planes de austeridad a las naciones en crisis, parcialmente es fruto de algunas vivencias en su natal República Democrática Alemana, actualmente disuelta. ${ }^{71}$

El nivel de análisis estatal, se caracteriza por prestar especial atención a cuestiones como las formas de gobierno, los intereses nacionales y el sistema económico imperante.

Respecto a esta categoría, podrían señalarse dos principales perspectivas, ya que por un lado la crisis económica en la UE puede considerarse como producto del mal manejo de la política económica de algunas naciones y, por ello aparentemente la austeridad es la solución para que las economías de otras naciones no se vean afectadas. ${ }^{72}$

Por otra parte, puesto que la Unión Europea, constituye una comunidad supranacional compuesta por diversos Estados, tales deberían ayudarse entre sí cuando fuese necesario, incluso a través del pago de las deudas particulares por la totalidad de los miembros. Finalmente, en el nivel internacional de análisis son tomados como principales referentes las fortalezas y debilidades de las organizaciones regionales e internaciones. ${ }^{73}$

Con base en lo anterior, es posible especular que el liderazgo alemán en la política económica, forma parte de la incapacidad manifestada por la UE para resolver como institución la crisis, puesto que su dependencia del presupuesto alemán, en ocasiones han ocasionado que la nación germana ocasionalmente dicte los lineamientos para resolver las problemáticas financieras, a pesar de la inconformidad de algunos miembros de la comunidad europea.

\footnotetext{
${ }^{69}$ Jourdy James Heredia, Situación económica, pp. 24-28.

${ }^{70}$ Karen Mingst, Fundamentos de las Relaciones Internacionales, Ciudad de México, Centro de Investigación y Docencia Económicas (CIDE) Ed., 2006, pp. 112-115.

${ }^{71}$ Pol Morrillas, Angela Merkel, Barcelona, CIDOB Ed., 2013, pp. 14-16.

${ }^{72}$ Esther Barbé, Relaciones Internacionales, Barcelona, Tecnos Ed., 2007, pp. 64-69.

${ }^{73}$ Karen Mingst, Fundamentos de las Relaciones, pp. 112-116.
} 
Aunque la UE sigue figurando como uno de los centros de poder significativos a nivel global, ello sólo ha sido gracias a la integración de las naciones que la conforman. Esto se debe a que después de varios siglos de haber constituido el principal núcleo económico-político del mundo, Europa manifestó su decadencia a mediados del siglo XX, ya que las naciones del viejo continente se encontraron frente a una realidad en la que los Estados Unidos y la Unión Soviética se erigieron como los principales actores internacionales, desplazando a las clásicas potencias de centurias precedentes. $^{74}$

Asimismo, la Unión Europea ha sido estimada como el sistema de integración regional más avanzado en el mundo durante el presente siglo, destacando como el único organismo supranacional global que ha permitido la colaboración de sus naciones y su fortalecido su cohesión mediante cierta transferencia de soberanía por sus Estados constituyentes, caso palpable en sectores como el comercio y la agricultura. ${ }^{75}$

En años recientes han sido diversos los Estados con deseos de ingresar a la UE, destacando hasta ahora Croacia como el último miembro admitido en el sistema de integración regional (2013). Sin embargo, para algunos analistas el futuro de la Europa comunitaria continúa siendo incierto, puesto que, entre otros dilemas, ha pasado de una producción del $26 \%$ del producto industrial mundial en 1980, a no superar el $17 \%$ de la misma en el presente siglo. ${ }^{76}$

Por lo expresado, hoy como hace ocho décadas, cabe recordar lo señalado por John Maynard Keynes, pues: "los principales inconvenientes de la sociedad económica en que vivimos son su incapacidad para procurar la ocupación plena y su arbitraria y desigual distribución de la riqueza y los ingresos." 77

\section{Conclusiones}

Actualmente, el euro continúa siendo una moneda fuerte a nivel global, pero aún en el presente las economías de la UE manifiestan diferentes problemáticas, al tiempo que el rol de Alemania en la eurozona ha sido uno de los temas más controversiales en la historia reciente, puesto que en diversas ocasiones las capacidades de dicho Estado se han impuesto sobre las perspectivas de las instituciones de la UE y sus Estados miembros.

En este sentido, la adopción o imposición de algunas políticas puede ser determinante para afectar o coadyuvar en el desarrollo económico de las naciones, ya sea de acuerdo a lo estipulado por la mayoría o a los intereses de

\footnotetext{
${ }^{74}$ Rafael Calduch Cervera, Relaciones Internacionales, Madrid: Ciencias Sociales, 1991, 2-3; Amartya Kumar Sen, ¿Qué le pasó, 54 ?

75 Esther Barbé, Relaciones Internacionales, 206,207, 260.

${ }^{76}$ Anthony Giddens, Europa en la era global, Paidós: Barcelona, 2007), 45-49; Ebeling Dieter, Armando Castilla (ed.), Ingresa Croacia a la UE, (Ciudad de México: Vanguardia, 2013), http://www.vanguardia.com.mx/ingresacroaciaalaue1773958.html (Fecha de consulta: 21/07/2018).

${ }^{77}$ John Maynard Keynes, Teoría general de la ocupación, el interés y el dinero, Distrito Federal, Fondo de Cultura Económica Ed., 2014, p. 349 (1ª ed. 1936).
} 
los que cuentan con las mayores capacidades. Asimismo, por la interdependencia existente en el mundo actual, es posible apreciar que el poder económico puede otorgar fuerza política, al tiempo que la influencia gubernamental produce consecuencias económicas.

Podemos apreciar que las políticas que se están llevando en la UE, probablemente no son las más adecuadas para las naciones en crisis, puesto que como se ha señalado, mientras la economía alemana ha mejorado, otros países de Europa han desacelerado su crecimiento, al tiempo que el proyecto de integración europeo ya ha manifestado algunos fracasos, como la salida de Gran Bretaña de la UE y el referendo a favor de dejar la eurozona por parte de Grecia.

Asimismo, el continente europeo, figura hoy en día como un espacio donde se cuenta con gran riqueza cultural, educativa y plural, pero que también adolece de factores como un bono demográfico o una cultura laboral con ocupación de suficientes horas en diversas naciones.

Puesto que la interdependencia se ha vuelto un fenómeno cada vez más frecuente desde el pasado siglo, es posible especular que la Unión Europea, es el producto de un proceso histórico, donde la necesidad de unir fortalezas e ideales ha servido a las naciones de Europa para la preservación de un status geopolítico, constituyendo un frente significativo a las potencias que surgieron durante la guerra fría.

\section{Bibliografía}

Barbé, Esther. Relaciones Internacionales. Barcelona: Tecnos, 2007.

Bertuch, Axel y Parmeshwar Ramlogan. "The euro ever more global". Finance and Development. Vol. 44. No. 1 (2007): 46-49.

Calduch Cervera, Rafael. Relaciones Internacionales. Madrid: Ciencias Sociales, 1991.

Cárdenas, Enrique. El largo curso de la economía mexicana. De 1780 a nuestros días. Ciudad de México: El Colegio de México-FCE, 2015.

Comisión Europea. Comunidad Europea (ed.). La historia de la Unión Europea. Madrid: Dirección General de Prensa y Comunicación de la UE, 2005.

Consejo Europeo, Unión Europea (ed.). Declaración de los Jefes de Estado y de Gobierno de la Zona del Euro. Bruselas: Dirección General de Prensa y Comunicación de la 2011. http://www.consilium.europa.eu/uedocs/cms_data/docs/pressdata/es/ec/126673.p $\underline{\mathrm{df}}$ 
Cruz Miramontes, Rodolfo. Las relaciones comerciales multilaterales de México y el Tratado de Libre Comercio con la Unión Europea. Ciudad de México: Universidad Nacional Autónoma de México, 2003.

Dieter, Ebeling, Armando Castilla (ed.). Ingresa Croacia a la UE. Ciudad de México: Vanguardia, 2013. http://www.vanguardia.com.mx/ingresacroaciaalaue1773958.html

Heller, Fernando, El mundo (eds.). Berlín sigue marcando el paso. Buenos Aires: La Nación, 2010. http://www.lanacion.com.ar/1272904-berlin-sigue-marcando-elpaso

Fernández Álvarez, Antonio. "El fondo europeo de inversiones: pieza clave de la financiación pyme en la Unión Europea", Boletín Económico de Información Comercial Española (BICE). No. 3014 (2011): 21-32.

Giddens, Anthony. Europa en la era global. Paidós: Barcelona, 2007.

James Heredia, Jourdy. Informe sobre la Evolución de la Economía Mundial 2012. La Habana: Centro de Investigaciones de la Economía Mundial, 2013.

Jarufe, Juan Pablo y Scharrer, Nicole, Biblioteca del Congreso Nacional de Chile (ed.). Crisis económica europea: origen, alcances y principales actores involucrados. Santiago de Chile: Comisión Permanente de Relaciones Exteriores, 2012. http://resmn.es/crisis-econmica-europea-origen-alcances-y-principalesactores.html

Keohane, Robert. Interdependencia, cooperación y globalismo. Ensayos sobre las Instituciones Internacionales. Ciudad de México: CIDE, 2005.

Keohane, Robert y Joseph Nye. "La interdependencia en la política mundial". En Ensayos escogidos de Robert O. Keohane, editado por Arturo Borja Tamayo. Ciudad de México: Centro de Investigación y Docencia Económicas, 2009, 91124.

Keynes, John Maynard. Teoría general de la ocupación, el interés y el dinero. Distrito Federal: Fondo de Cultura Económica, 2014 (1 ${ }^{\mathrm{a}}$ ed. 1936).

Krugman, Paul, Ecoprensa (Eds.). A menos que España abandone el euro está condenada a años de paro elevado. Madrid, El Economista España, 2012. http://www.eleconomista.es/espana/noticias/4286867/09/12/Paul-Krugman-Amenos-que-Espana-abandone-el-euro-esta-condenada-a-anos-de-paroelevado.html

Krugman, Paul, New York Times News (Eds.). Grecia, España y el euro. Quito: $E l$ Universo, 2010. http://www.eluniverso.com/2010/02/19/1/1363/grecia-espanaeuro.html

Krugman, Paul, New York Times News (Eds.). ¿Realmente se salvará al euro?, Quito: $\quad$ El Universo, 2012. http://www.eluniverso.com/2012/08/08/1/1363/realmente-salvara-euro.html 
Kuntz Ficker, Sandra. Historia económica general de México. Distrito Federal, El Colegio de México-Secretaría de Economía Ed., 2010.

Llorca, Eva, La Nueva España (eds.). Solicitar un crédito en España, ¿misión imposible? Asturias: Grupo Editorial Prensa Ibérica, 2012. http://www.Ine.es/finanzas-personales/2012/09/26/solicitar-credito-espanamision-imposible/1303653.html

Local Europe, European consulting (eds.), Banco Europeo de Inversiones. Madrid: Green Europe, 2013. http://greeneurope.es/docs/Banco\%20Europeo\%20de\%20Inversiones\%202013.p $\underline{\mathrm{df}}$

Marichal, Carlos. Nueva historia de las grandes crisis financieras: una perspectiva global 1873-2008. Ciudad de México: Debate, 2010.

Ménard, Claude y Mary Shirley. Handbook of New Institutional Economics. Berlin: Springer-Verlag, 2005.

Mingst, Karen. Fundamentos de las Relaciones Internacionales, Ciudad de México: Centro de Investigación y Docencia Económicas, 2006.

Morata, Francesc, La Unión Europea. Procesos, actores y políticas, Barcelona: Ariel, 1999.

Morrillas, Pol. Angela Merkel. Barcelona: CIDOB, 2013.

North, Douglass. Instituciones, cambio institucional y desempeño económico. Distrito Federal: Fondo de Cultura Económica, 2012.

Pérez, Claudi. Agencia Reuters eds. Alemania marca el paso en la UE. Madrid: El País, 2012. http://economia.elpais.com/economia/2012/12/06/actualidad/13548268879934 $\underline{06 . h t m l}$

Portafolio: Noticias de economía y negocios en Colombia y el Mundo, Ricardo Ávila (ed.), Radiografía de la crisis en la eurozona. Bogotá: Centro de información económica, 2012. http://www.portafolio.co/especiales/crisis-en-europa.

Sanz, Elena, El confidencial (eds.). La agonía de tres mercados inmobiliarios: España, Grecia e Irlanda. Madrid: Titania, 2011. http://www.elconfidencial.com/vivienda/2011-10-13/la-agonia-de-tresmercados-inmobiliarios-espana-grecia-e-irlanda_209477/

Saving, Jason, “Integration and Globalization: The European Bellwether". Economic Letter. Vol. 1. No. 5 (2006), 1-8.

Sen, Amartya Kumar. "¿Qué le pasó a Europa? La democracia y los banqueros”. Nexos, No. 418, (2012), 54-56. 
Unión Europea, Informe Anual de Actividades 2007. Luxemburgo, Oficina de publicaciones oficiales de las comunidades europeas-Tribunal de Cuentas Europeo, 2008.

Villasana Villalobos, Ramiro y Rafael Salvador Espinosa Ramírez. La inversión extranjera directa española en México: fundamentación y retrospectiva (19502013). Guadalajara: Universidad de Guadalajara Ed., 2015.

Waltz, Kenneth. El poder y las relaciones internacionales. México Distrito Federal: Centro de Investigación y Docencia Económicas (CIDE), 2005.

Wyborcza, GAZETA, Unión Europea (ed.), UNIÓN EUROPEA: El fin de la Europa alemana. Varsovia: Vox europ, 2012. http://www.voxeurop.eu/es/content/article/2220431-el-fin-de-la-europa-alemana 